\title{
Determination of Protein Concentration in Raw Milk by Mid-Infrared Fourier Transform Infrared/Attenuated Total Reflectance Spectroscopy
}

\author{
Y. Etzion, ${ }^{1}$ R. Linker, ${ }^{2}$ U. Cogan, ${ }^{3}$ and I. Shmulevich ${ }^{2}$ \\ ${ }^{1}$ The Interdisciplinary Program of Biotechnology, \\ ${ }^{2}$ Department of Civil and Environmental Engineering, \\ ${ }^{3}$ Department of Biotechnology and Food Engineering, \\ Technion-Israel Institute of Technology, Haifa, Israel
}

\section{ABSTRACT}

This study investigates the potential use of attenuated total reflectance spectroscopy in the mid-infrared range for determining protein concentration in raw cow milk. The determination of protein concentration is based on the characteristic absorbance of milk proteins, which includes 2 absorbance bands in the 1500 to 1700 $\mathrm{cm}^{-1}$ range, known as the amide I and amide II bands, and absorbance in the 1060 to $1100 \mathrm{~cm}^{-1}$ range, which is associated with phosphate groups covalently bound to casein proteins. To minimize the influence of the strong water band (centered around $1640 \mathrm{~cm}^{-1}$ ) that overlaps with the amide I and amide II bands, an optimized automatic procedure for accurate water subtraction was applied. Following water subtraction, the spectra were analyzed by 3 methods, namely simple band integration, partial least squares (PLS) and neural networks. For the neural network models, the spectra were first decomposed by principal component analysis (PCA), and the neural network inputs were the spectra principal components scores. In addition, the concentrations of 2 constituents expected to interact with the protein (i.e., fat and lactose) were also used as inputs. These approaches were tested with 235 spectra of standardized raw milk samples, corresponding to 26 protein concentrations in the 2.47 to $3.90 \%$ (weight per volume) range. The simple integration method led to very poor results, whereas PLS resulted in prediction errors of about $0.22 \%$ protein. The neural network approach led to prediction errors of $0.20 \%$ protein when based on PCA scores only, and $0.08 \%$ protein when lactose and fat concentrations were also included in the model. These results indicate the potential usefulness of Fourier transform infrared/attenuated total reflectance spectroscopy for rapid, possibly online, determination of protein concentration in raw milk.

Received March 9, 2004.

Accepted May 3, 2004.

Corresponding author: R. Linker; e-mail: linkerr@tx.technion.ac.il.

(Key words: raw milk, mid-infrared, attenuated total reflectance, Fourier transform infrared spectroscopy)

Abbreviation key: ATR = attenuated total reflectance, $\mathbf{A U}=$ absorbance units, FTIR = Fourier transform infrared, IR = infrared, $\mathbf{M I R}=$ mid infrared, $\mathbf{N N}=$ neural networks, PCA $=$ principal component analysis, PLS = partial least squares.

\section{INTRODUCTION}

Milk's value is determined primarily by its protein and fat contents (Swaisgood, 1996). Unfortunately, to date, online determination of protein concentration during the milking process, which would enable optimal farm management, is not available. The goal of this study was to investigate the potential use of attenuated total reflectance (ATR) spectroscopy in the mid-infrared (MIR) range for online measurement of protein concentration.

Infrared (IR) spectroscopy expresses typical vibration modes of covalent bonds in molecules, and thus contains quantitative information about all the constituents that absorb IR radiation, including proteins. Fourier transform infrared (FTIR) spectroscopy is routinely used by laboratories specializing in milk analysis because it is a fast, nondestructive, and easy procedure that enables simultaneous measurement of several components in a complex natural media (Griffiths and deHaseth, 1986; Andersen et al., 2002). The MIR range (wave number range 400 to $4000 \mathrm{~cm}^{-1}$, equivalent to the 2.5 - to $25-\mu \mathrm{m}$ wavelength range) is especially attractive since measurements in this range provide direct information concerning the specific constituents in the sample, as well as their characteristic molecular structure. However, the use of the MIR spectrum for quantitative analysis of protein components is difficult for 2 main reasons. First, water, which is the continuous phase in milk as well as in many other biological media, has intense absorbance bands centered on approximately $1640 \mathrm{~cm}^{-1}$ (resulting from $\mathrm{H}_{2} \mathrm{O}$ bending vibrations) and $3300 \mathrm{~cm}^{-1}$ (resulting from $\mathrm{O}-\mathrm{H}$ stretching vibrations) 
(Libnau et al., 1994). The first water band overlaps with much smaller bands characteristic of proteins, known as amide I and amide II, which are located in the 1600 to 1700 and 1550 to $1570 \mathrm{~cm}^{-1}$ ranges, respectively (Susi, 1969; Jung, 2000). These bands result from different combinations of vibrations in the peptide bonds, and have a major role in protein analysis by MIR spectroscopy (Curley et al., 1998). Second, the formation of both intra- and intermolecular hydrogen bonds by proteins affects the position, magnitude, and shape of the amide bands. Since hydrogen bonds are sensitive to a number of factors, such as temperature, protein concentration, and ionic strength of the media, the amide bands are influenced by the protein environment (Dousseau and Pézolet, 1990; Coates, 2000; Grdadolnik and Maréchal, 2001).

The strong absorbance of water in the MIR range has led to the development of 1 ) digital processing methods for subtracting the water spectrum, and 2) adequate measurement configurations. Automatic procedures for subtracting the water contribution to the spectrum of protein solutions have been developed by, for example, Powell et al. (1986), Dousseau et al. (1989), and Rahmelow and Hübner (1997). The best results were reported by Rahmelow and Hübner (1997), with residual errors of 0.006 absorbance units (AU) at $1650 \mathrm{~cm}^{-1}$, which is close to the location of the amide I band. This residual error is still significant, since, for comparison, the maximal intensity of amide I for $3 \%$ protein solutions in water is less than $0.04 \mathrm{AU}$. Also, with respect to the measurement configuration, most of the studies related to MIR spectroscopy for protein analysis, as well as with commercial spectrophotometers used for daily laboratory analysis, are based on thin transmittance cells for which the optic path is typically less than 10 $\mu \mathrm{m}$ (Dousseau et al., 1989; Hewavitharana and Brakel, 1997). In such configurations, water absorbance is reduced to approximately one order of magnitude higher than protein absorbance. However, such thin transmittance cells are suitable only for laboratory batch analysis, and not for continuous online analysis in milking lines. A different approach consists of measuring reflectance from the sample. A commonly used method is the diffuse reflectance method, which is based on random reflections from particles in the sample. This approach was used by Schmilovich et al. (2000) to determine fat content in milk, using the near infrared range. The difficulty with this approach stems from the considerable effect that particle size, shape, density, and distribution have on the spectrum. This complicates the analysis of protein in milk, which contains fat globules that are at least one order of magnitude larger than the casein micelles. Another method based on reflectance is the ATR method, in which the IR radiation is not guided

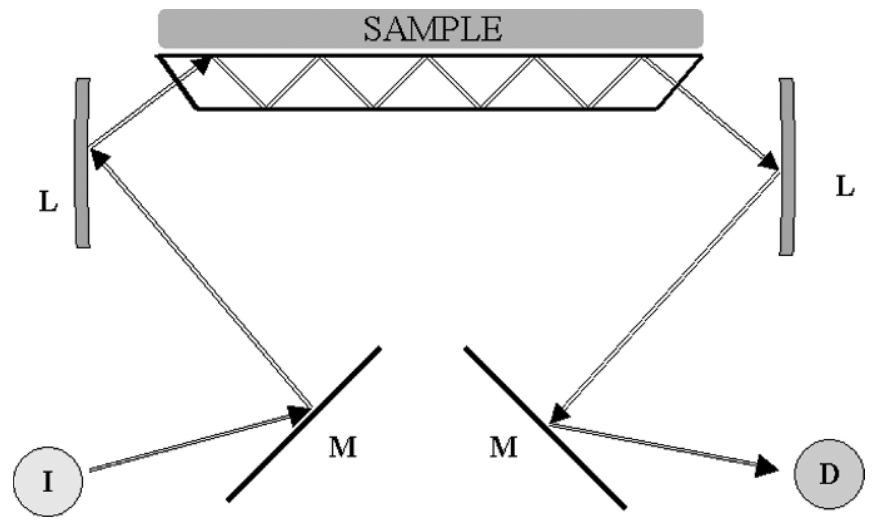

Figure 1. Schematic representation of attenuated total reflectance (ATR) configuration. I is the light source (interferometer), D is the detector, and $\mathrm{L}$ and $\mathrm{M}$ are focusing lenses and mirrors, respectively. The arrows represent the infrared beam course.

through the sample itself, but rather through a crystal with a high refractive index that is in contact with the sample (Figure 1). The beam is reflected several times inside the crystal before being directed to the detector. When the beam hits the reflecting surface, it penetrates into the sample up to a depth of approximately $0.1 \lambda$, where $\lambda$ is the wavelength of the radiation. For MIR, the penetration depth is less than $10 \mu \mathrm{m}$, which is similar to thin transmittance cells. However, by comparison to transmission cells, repeatability is enhanced because sample dimensions do not affect the optic path (Melling and Thompson, 2002). A more detailed explanation of ATR principles and characteristics can be found, for instance, in Chittur (1998). Note that for online applications, the set-up depicted in Figure 1 can be easily modified to work with immersed ATR crystals that are commercially available. Ultimately, the ATR crystal could be avoided by using fiber optics-based sensors (fiber optics evanescence wave spectroscopy; Messica et al., 1996) that are currently under development.

The combination of MIR ATR and automatic water subtraction has been successfully used for investigating protein structure in water solutions or buffers (e.g., Chittur, 1998; Curley et al., 1998). The goal of this study is to investigate the potential use of such a configuration for the determination of protein concentration in raw milk.

\section{MATERIALS AND METHODS}

\section{Sample Preparation}

The study involved measurements with 3 types of media: aqueous casein solutions, raw milk standards, and fresh raw milk. Casein was chosen as a model for 
milk protein because it comprises $78 \%$ of the protein in cow's milk (DePeters and Ferguson, 1992). Prior to ATR measurements, all the samples, including water and casein suspensions, were warmed in a water bath to $39 \pm 1{ }^{\circ} \mathrm{C}$, which is above the melting point of the milk fat. The ATR crystal was cleaned of fat and protein residues between samples using deionized water and 5\% ES-7X cleaning solution (ICN Biomedicals, Inc.).

Aqueous solutions. A stock solution of $8 \%(\mathrm{wt} / \mathrm{vol})$ casein in water was prepared from sodium caseinate powder (product No. C-8654 from Sigma Chemical Co., St. Louis, MO), including the addition of 2-bromo-2 nitropropane-1,3-diol $(20 \mathrm{mg} / 100 \mathrm{~mL})$ and Natamicin $(0.75 \mathrm{mg} / 100 \mathrm{~mL})$ as a preservative. The $\mathrm{pH}$ of the suspension remained stable at 6.8 during refrigerated storage. Samples containing 1.8 to $5.4 \%$ (wt/vol) casein and at $\mathrm{pH} 6.7$ were prepared by diluting stock solution with deionized water, immediately before ATR measurements.

Milk standards. To obtain milk samples with various protein-fat combinations, standards were prepared from raw cow milk at the Central Laboratory for Milk Analysis in Park Caesarea, Israel. Milk bulks were fractionated into high-fat ( $\sim 3 \%$ protein, $\sim 10 \%$ fat), low-fat ( $\sim 3 \%$ protein, $<1 \%$ fat), and high-protein fractions $(\sim 5 \%$ protein, $\sim 1.5 \%$ fat), and filtrate with negligible contents of protein and fat. These fractions were then mixed so as to obtain a set of 26 milk standards with various protein and fat concentrations. The exact composition of these standards (Table 1) was determined at the same laboratory using a Foss Milkoscan 605/255 spectrophotometer calibrated vs. analytically determined protein (Kjeldahl), fat (Röse-Gottlieb), and lactose (Boehringer-Mannheim) concentrations. As can be verified in Table 1, special care was taken to create standards with concentrations representative of real cow milk.

Fresh raw milk. Fresh raw milk samples were obtained from 10 cows at the Kfar-Galim dairy farm (KfarGalim, Israel) The cows were milked manually, and following the addition of 2-bromo-2 nitropropane-1,3$\operatorname{diol}(20 \mathrm{mg} / 100 \mathrm{~mL})$ and Natamicin $(0.75 \mathrm{mg} / 100 \mathrm{~mL})$, samples were refrigerated at $4^{\circ} \mathrm{C}$ until ATR measurements were taken later the same day.

\section{Spectral Measurements}

The FTIR measurements were performed with a Vector 22 spectrophotometer (Bruker, Inc. Ettlingen, Germany), equipped with a mercury cadmium telluride detector and a bath-shaped germanium horizontal ATR crystal (Pike Technologies). To avoid interferences due to water vapor in the optic path, dried pressurized air was constantly circulated through the spectrophotometer, thus maintaining the relative humidity below $10 \%$
Table 1. Composition of the milk standards.

\begin{tabular}{llll}
\hline $\begin{array}{l}\text { Standard } \\
\text { number }\end{array}$ & $\begin{array}{l}\text { Protein } \\
(\%)\end{array}$ & $\begin{array}{l}\text { Fat } \\
(\%)\end{array}$ & $\begin{array}{l}\text { Lactose } \\
(\%)\end{array}$ \\
\hline 1 & 3.23 & 4.18 & 4.99 \\
2 & 3.66 & 3.45 & 4.93 \\
3 & 3.08 & 5.63 & 4.78 \\
4 & 2.57 & 2.75 & 4.39 \\
5 & 2.53 & 3.34 & 5.45 \\
6 & 3.73 & 4.96 & 4.89 \\
7 & 2.47 & 2.04 & 4.99 \\
8 & 3.81 & 3.19 & 4.88 \\
9 & 3.10 & 3.56 & 4.83 \\
10 & 3.10 & 4.58 & 4.83 \\
11 & 3.10 & 2.55 & 4.79 \\
12 & 3.11 & 3.79 & 4.92 \\
13 & 3.15 & 3.59 & 4.91 \\
14 & 3.41 & 4.37 & 4.87 \\
15 & 3.20 & 6.18 & 4.79 \\
16 & 2.60 & 3.32 & 5.42 \\
17 & 2.91 & 2.77 & 4.37 \\
18 & 3.95 & 5.03 & 4.83 \\
19 & 2.92 & 2.63 & 4.99 \\
20 & 2.90 & 3.13 & 4.77 \\
21 & 3.28 & 3.16 & 4.95 \\
22 & 3.36 & 3.30 & 4.85 \\
23 & 3.35 & 5.95 & 4.76 \\
24 & 3.86 & 4.12 & 4.82 \\
25 & 3.15 & 2.95 & 4.95 \\
26 & 2.58 & 3.11 & 5.41 \\
\hline
\end{tabular}

during the measurements. Each measurement included 32 double-sided scans in the 1000 to $4000 \mathrm{~cm}^{-1}$ range, with a resolution of $2 \mathrm{~cm}^{-1}$. A background measurement (air) was recorded immediately before each measurement, and the interferogram was transformed into an ATR spectrum using the software operating the spectrophotometer (OPUS NT version 3.0), using the Norton Bear weak apodization function and the Mertz phasecorrection method. In addition to the spectra of casein solutions and milk samples, 28 spectra of pure deionized water were also recorded, and the average water spectrum recorded on a given day served as the reference when applying the water subtraction procedure to the same day spectra (see below). For the experiment with milk standards, the spectra of 235 samples taken from the 26 standards were recorded. For the experiment with fresh milk, the sample from each cow was subsampled 3 times ( 3 spectra per cow).

\section{Data Processing}

Data postprocessing involved 2 stages. First, the water contribution to the spectrum was removed. Second, chemometric methods (Wold, 1995) and neural networks were used to correlate the protein concentration to the water-subtracted spectrum.

Water subtraction. A procedure similar to the one described by Rahmelow and Hübner (1997) was used 


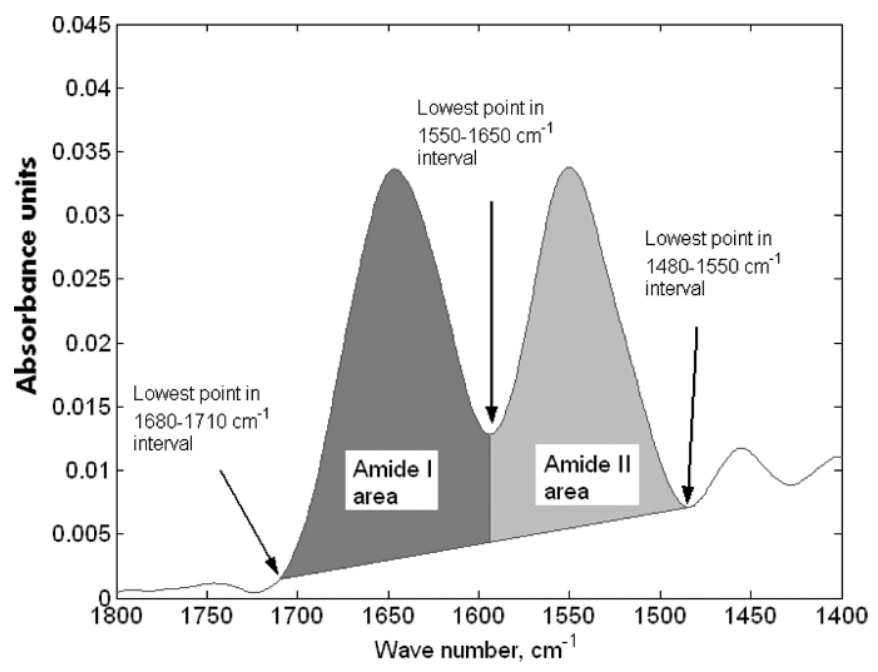

Figure 2. Typical spectrum of aqueous solution containing 6\% protein (after water subtraction), and definition of the integrals calculated over the amide I and II ranges.

to subtract the water contribution. This procedure can be summarized as follows: 1) Choose an interval in which the measured spectrum is due to water only (not affected by protein or other milk constituents). 2) For each spectrum, determine the scaling coefficient such that, in the interval chosen, the difference between the measured spectrum and the scaled reference water spectrum is as close as possible to a straight line. This straight line is the residual baseline. 3) After removing the scaled water spectrum from the measured spectrum, remove the residual baseline.

Protein quantification. Protein quantification was attempted using 3 different approaches: simple integration of the amide bands, partial least squares (PLS), and principal components analysis (PCA) followed by a neural network (NN). To prevent overfitting, all of the models were calibrated using only 181 of the 235 measurements performed with milk standards (chosen randomly). In all of the tables, the accuracy of the models is presented in terms of the root mean square prediction error (RMSE) of all the data:

$$
R M S E=\sqrt{\frac{\sum_{i=1}^{N}\left(y-y^{\prime}\right)^{2}}{N}}
$$

where $y$ and $y^{\prime}$ are the predicted and actual protein concentrations, and $\mathrm{N}$ is the number of samples.

Integration of the amide I and II bands was performed between local minima of the spectra, as shown in Figure 2. The PLS method (Haaland and Thomas, 1988) is routinely used in spectrometry, and will not be detailed here. Basically, the spectra are decomposed into so-called principal components, and a linear relationship is calibrated between the coefficients of these principal components (so-called scores) and the concentration of interest.

The third method consisted of a combination of PCA (Jolliffe, 1986) and NN. Neural networks have become popular as "black-box" models that can approximate any nonlinear relationship between input and output variables (Haykin, 1999). With respect to spectroscopy, $\mathrm{NN}$ have been used in conjunction with PCA, and in such cases, the PCA scores are used as inputs of the NN (e.g., Mariey et al., 2001; Ruckebusch et al., 2001; Fidencio et al., 2002). In addition, because the NN can accommodate inputs of different natures, it is possible to include "nonspectral" inputs, such as lactose or fat concentrations, which are expected to affect the relationship between the protein concentration and the measured spectra. A schematic representation of such a model is shown in Figure 3. A NN includes a large number of parameters that are calibrated during the so-called training procedure (calibration phase). The final values of these parameters, and therefore the model itself, depend, to a certain extent, on the initial parameter values, especially when the calibration set is relatively small, as in the present case. Because it is not possible to determine a priori "good" initial values, each model was calibrated 10 times starting from different random values, and only the model that gave the best results on the validation set (54 samples) was retained.

\section{RESULTS AND DISCUSSION}

\section{Residual Error After Water Subtraction}

The procedure for water subtraction and baseline correction requires the choice of the wave number interval over which the subtraction factor is calculated. As suggested by Rahmelow and Hübner (1997), the best interval was determined by applying the procedure to pure water spectra and calculating the residual error in the absorbance region of amide I and II. The results are presented in Table 2. The smallest residual error was obtained using the 1720 to $2280 \mathrm{~cm}^{-1}$ range as the subtraction interval, in which case the residual error was approximately $3 \mathrm{mAU}$ in the amide I region. Such an error is about one order of magnitude smaller than the amplitude of the amide I band associated with a $6 \%$ protein solution (Figure 2). It must also be noted that, contrary to Rahmelow and Hübner (1997), basing water subtraction on 2 intervals did not lead to smaller errors, probably because of high spectral noise at wave numbers higher than $2500 \mathrm{~cm}^{-1}$ due to residual water vapor. 


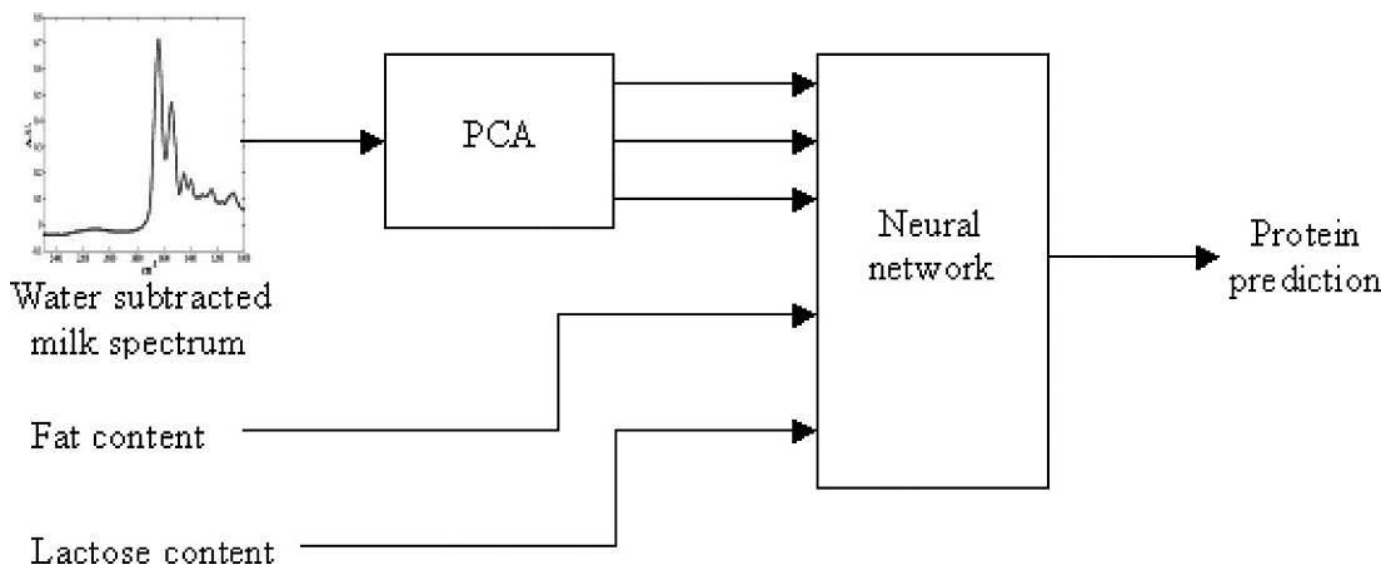

Figure 3. Schematic representation of a neural network model based on the scores of the principal component analysis (PCA) decomposition of the water-subtracted milk spectrum, and fat and lactose content.

\section{Measurements in Aqueous Solutions}

Figure 4 shows typical spectra of casein in aqueous solution after water subtraction and baseline correction. The amide bands are clearly visible, as is the $\mathrm{O}=$ $\mathrm{P}-\mathrm{O}$ stretch band characteristic of casein (Jung, 2000). As expected, the amplitude of these bands increases with increasing casein concentration. Also, in agreement to Chittur (1998), the repeatability of the signal improves from $3 \%$ protein and up. Figure 5 shows that there is a strong linear correlation between the integrals of the amide bands and the casein concentration. The slightly lower $\mathrm{R}^{2}$ value obtained when using only the amide I region (top right frame) agrees with the fact that the amide I band, which is the closest to the water band, is most likely to be affected by imperfect water subtraction. The ratio of the amide I and II areas was also calculated (bottom right frame in Figure 5), and, as expected, this ratio remains relatively constant.

\section{Measurements of Raw Milk}

Milk standards. Applying the simple integration procedure described above to water-subtracted milk spectra led to the results presented in Figure 6. Contrary to the results obtained in aqueous solution, there

Table 2. Residual error after applying the water subtraction procedure to spectra of pure de-ionized water, as calculated both in the range of amide I and II $\left(1500\right.$ to $\left.1700 \mathrm{~cm}^{-1}\right)$ and in a narrower range corresponding to the location of water absorbance overlapping the amide I band (1635 to $\left.1650 \mathrm{~cm}^{-1}\right)$. For comparison, the results of Rawmelow and Hübner (1997) are given in the last row. The smallest values of the residual errors are indicated in bold.

\begin{tabular}{|c|c|c|c|c|c|c|}
\hline & \multicolumn{4}{|c|}{$\begin{array}{l}\text { Interval for calculation of subtraction } \\
\text { factor and baseline correction }\end{array}$} & \multirow{2}{*}{\multicolumn{2}{|c|}{$\mathrm{RMSE}(\mathrm{mAU})^{1}$}} \\
\hline & \multicolumn{2}{|c|}{ First interval $\left(\mathrm{cm}^{-1}\right)$} & \multicolumn{2}{|c|}{ Second interval $\left(\mathrm{cm}^{-1}\right)$} & & \\
\hline & Start & End & Start & End & $\mathrm{cm}^{-1}$ & $\mathrm{~cm}^{-1}$ \\
\hline & 1700 & 2280 & - & - & 2.51 & 3.24 \\
\hline & 1720 & 2280 & - & - & 2.46 & 3.09 \\
\hline & 1740 & 2280 & - & - & 2.51 & 3.17 \\
\hline & 1760 & 2280 & - & - & 2.63 & 3.35 \\
\hline & 1700 & 2280 & 3650 & 4000 & 2.87 & 4.19 \\
\hline & 1750 & 2280 & 3650 & 4000 & 3.04 & 4.54 \\
\hline & 1750 & 2280 & 3700 & 4000 & 4.48 & 7.27 \\
\hline & 1750 & 2280 & 3800 & 4000 & 4.61 & 7.50 \\
\hline & 1750 & 2280 & 3900 & 4000 & 4.44 & 7.24 \\
\hline & 1800 & 2280 & 3650 & 4000 & 3.13 & 4.69 \\
\hline $\begin{array}{l}\text { Rahmelow and } \\
\text { Hübner (1997) }\end{array}$ & 1800 & 2300 & 3650 & 4000 & & $6.00-7.00$ \\
\hline
\end{tabular}

${ }^{1} \mathrm{RMSE}=$ root mean square error. $\mathrm{AU}=$ absorbance units. 

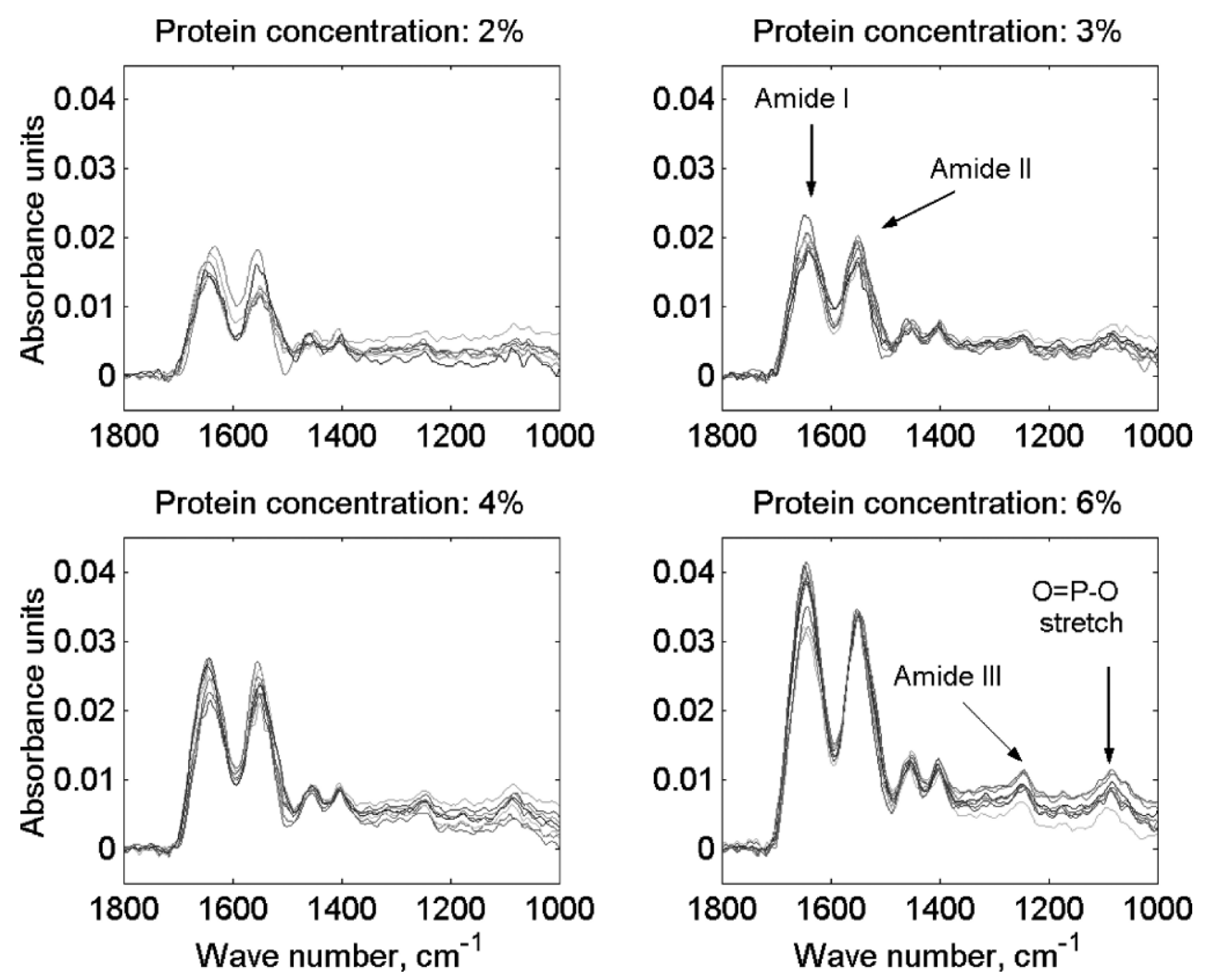

Figure 4. Water-subtracted spectra of casein aqueous solutions. Each frame corresponds to a different casein concentration (see frame header). For each concentration, 10 spectra are presented.

is no apparent correlation between the protein concentration and the integral of the amide I and/or II band. The absence of a correlation can be attributed to several factors. Change of ionic strength and interactions with sugars affect protein interactions with water (Timasheff and Fasman, 1969; Farhat et al., 1998) and modify its secondary structure (Curley et al., 1998; Ramon et al., 2001). Therefore, the protein and water spectra are altered, which also affects the accuracy of the water subtraction procedure (Rahmelow and Hübner, 1997; Grdadolnik and Maréchal, 2001). Since no attempt was made to make the salt content of the different samples uniform, it is likely that such effects occurred. Also, the vibrations of the $\mathrm{O}-\mathrm{H}$ groups in water are sensitive to interactions between water and other elements present in milk, like polar lipids and proteins, which affect the water contribution to the spectrum but are not taken into account in the subtraction procedure (Dousseau and Pézolet, 1990). In addition, the ATR spectrum reflects only the absorbance of the 5- to $10-\mu$ m layer in contact with the ATR crystal, and protein micelles may be obscured by fat globules (Chittur, 1998). As shown by Kemsley et al. (1994), expression of fat in ATR spectra is dependent on the size and distribution of fat globules, which are likely to differ among raw (nonhomogenized) samples.

Whereas adequate preprocessing of the milk (for instance, homogenization) could have reduced these effects, such methods would have prevented the use of the proposed technique for online measurement, which is the ultimate objective of this project. Therefore, improvements to the predictions were sought through more advanced analysis of the spectra, as detailed below.

Partial least squares analysis was applied to several intervals expected to include information related to protein content, namely 1558 to $1705 \mathrm{~cm}^{-1}$ (amide I), 1480 to $1613 \mathrm{~cm}^{-1}$ (amide II), 1200 to $1280 \mathrm{~cm}^{-1}$ (amide III), and 1060 to $1100 \mathrm{~cm}^{-1}(\mathrm{O}=\mathrm{P}-\mathrm{O}$ stretch $)$. Table 3 shows the results of the best combinations, using 5,7 , or 9 principal components. The best results are obtained using 9 principal components of the spectra in the amide II, amide III, and $\mathrm{O}=\mathrm{P}-\mathrm{O}$ stretch regions, or in the amide II and entire fingerprint region, which is consistent with the findings of Hewavitharana and Brakel (1997). In all cases but one (model based on amide I, amide III and phosphate stretch zones), adding the spectral zone of phosphate stretching band improves 

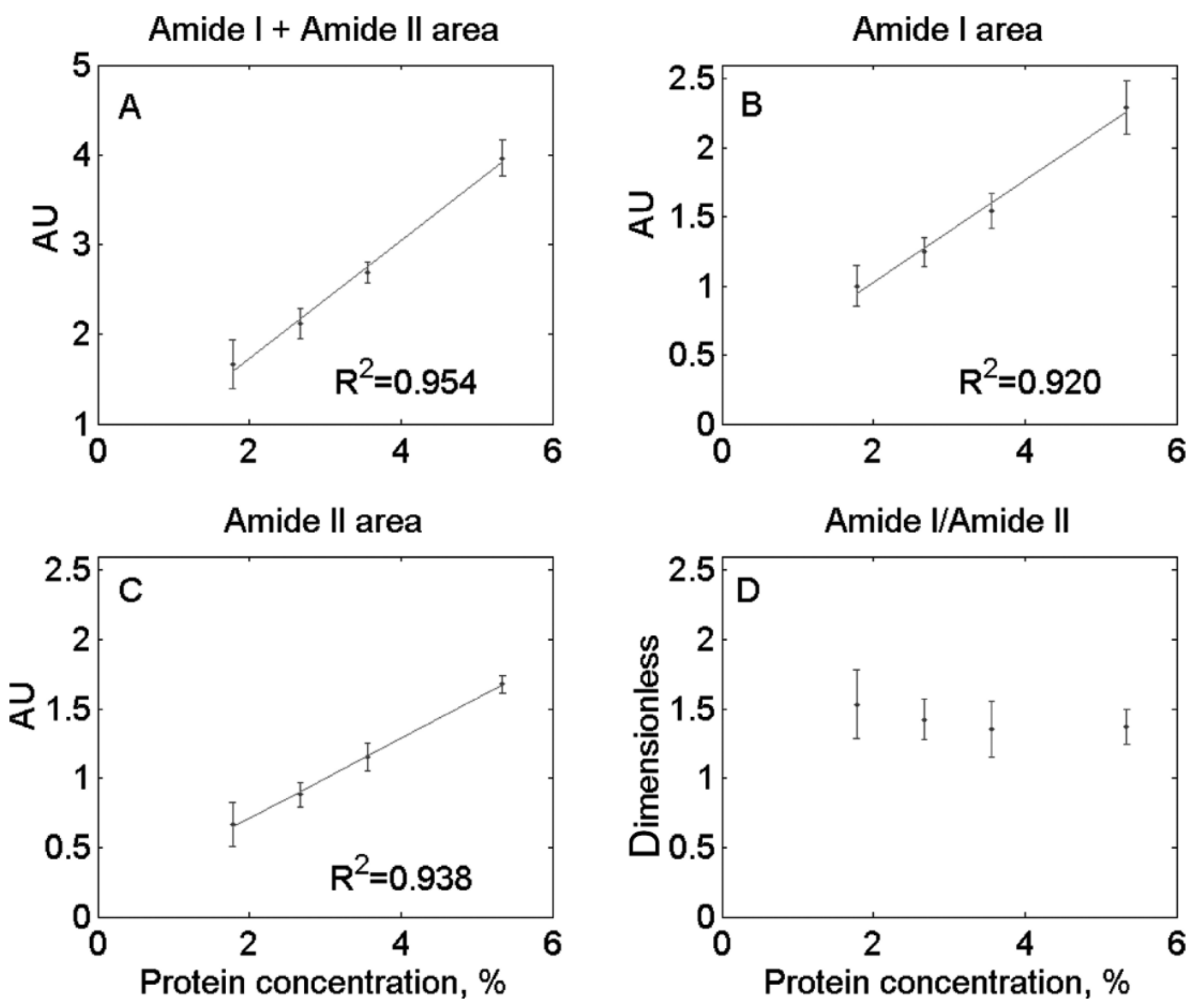

Figure 5. Results of the integration procedure applied to the water-subtracted spectra of aqueous casein solutions. Actual protein concentration vs. A) integral of the amide I+II bands (top left frame); B) integral of amide I band (top right frame); C) integral of amide II band (bottom left frame); and D) ratio of the integrals of the amide I and II bands (bottom right frame). Integration intervals as described in Materials and Methods Section.

protein prediction. However, the prediction error $(0.22 \%$ protein $)$ is still quite large.

The results obtained using PCA and NN are summarized in Table 4. Note that the number of PCA scores included in the NN inputs differed in some of the models, and was always such that at least $97 \%$ of the variance of the original spectrum was accounted for. When only the PCA scores are used as inputs, the results are similar to the ones obtained with PLS (Table 3), which indicates that adding nonlinear flexibility alone to the model is not sufficient. As mentioned earlier, one advantage of the $\mathrm{NN}$ is that inputs of a different nature can be used. Therefore, in an attempt to improve the predictions, the concentration of fat and/or lactose, which is expected to affect the spectrum, was added to the model inputs (Figure 3). In most cases, adding the lactose concentration alone leads to better results than adding the fat concentration alone, whereas adding both leads to the best results. The smallest prediction error $(0.08 \%$ protein) is obtained using both fat and lactose concentration, in addition to the PCA scores of the amide II and $\mathrm{P}=\mathrm{O}-\mathrm{P}$ stretch intervals.

Model validation using "fresh" milk. All the results presented in the previous section were based on milk standards prepared from fractionated raw milk. As a first step toward validation of the approach for online application, the best model obtained above (bold in Table 4) was used to predict the protein content of 10 samples of "fresh" cow milk. The results are presented in Table 5. Overall, these results are encouraging, with prediction error less than $0.5 \%$ protein, except for Cow 6. Furthermore, the poor prediction obtained for Cow 6 can be explained by the very high fat content, which is beyond the range of the calibration set. The large range of errors (from -0.05 to $0.49 \%$, Cow 6 excluded) may be partly attributed to the manual milking procedure, which caused "foaming," and may have re- 
Amide I+Amide II area

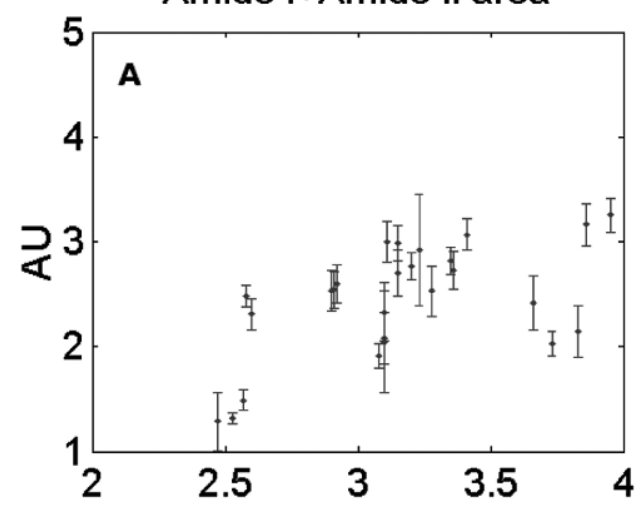

Amide II area

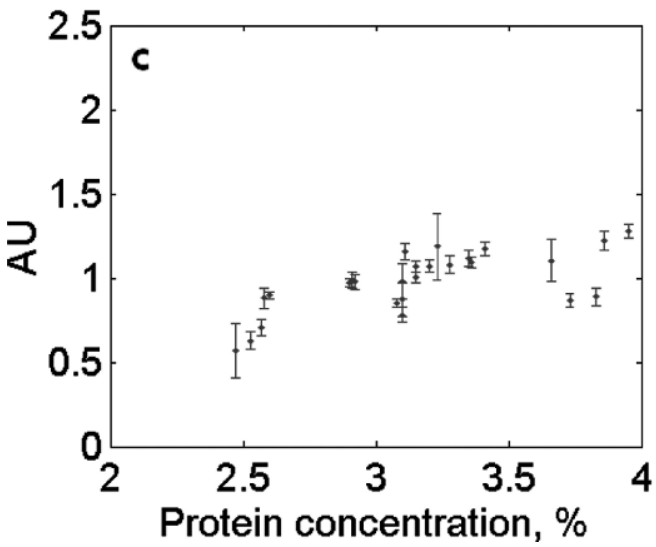

Amide I area

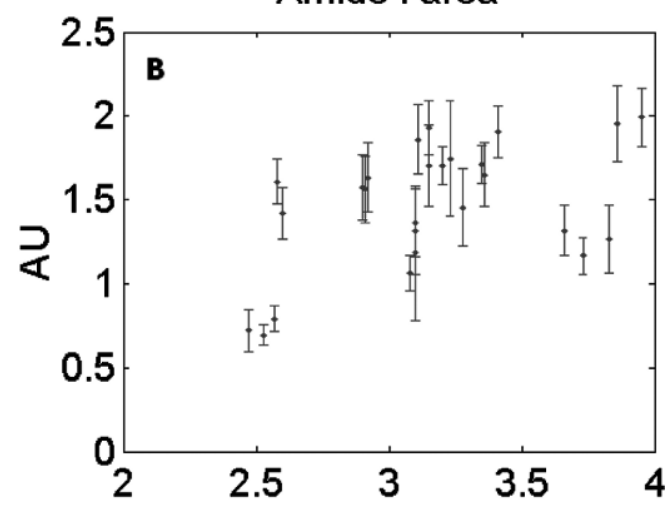

Amide I/Amide II

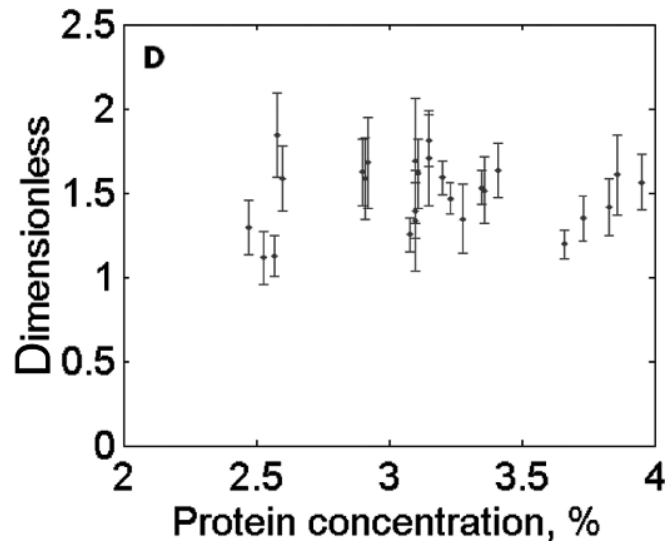

Figure 6. Results of the integration procedure applied to water-subtracted spectra of milk standards. Actual protein concentration vs. A) integral of the amide I+II bands (top left frame); B) integral of amide I band (top right frame); C) integral of amide II band (bottom left frame); D) ratio of the integrals of the amide I and II bands (bottom right frame). Integration intervals as described in Materials and Methods Section.

sulted in differences between the samples analyzed by FTIR and those sent for reference analysis. Another cause of error is that the model was calibrated using milk standards that were obtained from milk fractions that may differ physically, and possibly chemically, from fresh milk sample. Therefore, a model based on milk standards only is not necessarily optimized for fresh milk samples.

Table 3. Prediction errors of partial least squares models. ${ }^{1}$

\begin{tabular}{|c|c|c|c|c|c|c|}
\hline \multicolumn{4}{|c|}{ Spectral zone for PLS decomposition } & \multicolumn{3}{|c|}{ Root mean square error, $\%$ protein } \\
\hline \multirow{2}{*}{$\begin{array}{l}\text { Amide I } \\
1558-1705 \\
\mathrm{~cm}^{-1}\end{array}$} & \multirow{2}{*}{$\begin{array}{l}\text { Amide II } \\
1480-1613 \\
\mathrm{~cm}^{-1}\end{array}$} & \multirow{2}{*}{$\begin{array}{l}\text { Amide III } \\
1200-1280 \\
\mathrm{~cm}^{-1}\end{array}$} & \multirow{2}{*}{$\begin{array}{l}\mathrm{O}=\mathrm{P}-\mathrm{O} \text { stretch } \\
1060-1100 \\
\mathrm{~cm}^{-1}\end{array}$} & \multicolumn{3}{|c|}{ Number of principal components } \\
\hline & & & & 5 & 7 & 9 \\
\hline \multirow[t]{2}{*}{$\sqrt{ }$} & $\sqrt{ }$ & & & 0.28 & 0.27 & 0.26 \\
\hline & $\sqrt{ }$ & $\sqrt{ }$ & & 0.28 & 0.26 & 0.26 \\
\hline \multirow[t]{2}{*}{$\sqrt{ }$} & $\sqrt{ }$ & $\sqrt{ }$ & & 0.28 & 0.27 & 0.26 \\
\hline & $\sqrt{ }$ & & $\sqrt{ }$ & 0.26 & 0.24 & 0.23 \\
\hline \multirow[t]{2}{*}{$\sqrt{ }$} & $\sqrt{ }$ & & $\sqrt{ }$ & 0.27 & 0.25 & 0.23 \\
\hline & $\sqrt{ }$ & $\sqrt{ }$ & $\sqrt{ }$ & 0.24 & 0.23 & 0.22 \\
\hline \multirow[t]{2}{*}{$\sqrt{ }$} & & -5 & $\sqrt{ }$ & 0.29 & 0.27 & 0.26 \\
\hline & $\sqrt{ }$ & $1000-1300 \mathrm{~cm}^{-1}$ & & 0.24 & 0.22 & 0.22 \\
\hline
\end{tabular}

\footnotetext{
$1 \sqrt{ }$ indicates that the corresponding interval is included in the model. The lowest prediction error is indicated in bold.
} 
Table 4. Prediction errors of neural network models. ${ }^{1}$

\begin{tabular}{|c|c|c|c|c|c|c|c|}
\hline \multicolumn{4}{|c|}{ Spectral zone for PCA } & \multirow{2}{*}{\multicolumn{4}{|c|}{$\frac{\text { Root mean square error, } \% \text { protein }}{\text { Neural network inputs }}$}} \\
\hline \multirow{2}{*}{$\begin{array}{l}\text { Amide I } \\
1558-1705 \\
\mathrm{~cm}^{-1}\end{array}$} & \multirow{2}{*}{$\begin{array}{l}\text { Amide II } \\
1480-1613 \\
\mathrm{~cm}^{-1}\end{array}$} & \multirow{2}{*}{$\begin{array}{l}\text { Amide III } \\
1200-1280 \\
\mathrm{~cm}^{-1}\end{array}$} & \multirow{2}{*}{$\begin{array}{l}\mathrm{O}=\mathrm{P}-\mathrm{O} \text { stretch } \\
1060-1100 \\
\mathrm{~cm}^{-1}\end{array}$} & & & & \\
\hline & & & & PCA & $\begin{array}{l}\text { PCA and } \\
\text { fat }\end{array}$ & $\begin{array}{l}\text { PCA and } \\
\text { lactose }\end{array}$ & $\begin{array}{l}\text { PCA, fat, } \\
\text { and lactose }\end{array}$ \\
\hline \multirow[t]{2}{*}{$\sqrt{ }$} & $\sqrt{ }$ & & & 0.24 & 0.22 & 0.18 & 0.16 \\
\hline & $\sqrt{ }$ & $\sqrt{ }$ & & 0.25 & 0.23 & 0.12 & 0.14 \\
\hline \multirow[t]{2}{*}{$\sqrt{ }$} & $\sqrt{ }$ & $\sqrt{ }$ & & 0.23 & 0.19 & 0.12 & 0.11 \\
\hline & $\sqrt{ }$ & & $\sqrt{ }$ & 0.21 & 0.16 & 0.18 & 0.08 \\
\hline \multirow[t]{2}{*}{$\sqrt{ }$} & $\sqrt{ }$ & & $\sqrt{ }$ & 0.20 & 0.20 & 0.17 & 0.13 \\
\hline & $\sqrt{ }$ & $\sqrt{ }$ & $\sqrt{ }$ & 0.20 & 0.17 & 0.14 & 0.09 \\
\hline \multirow[t]{2}{*}{$\sqrt{ }$} & & & $\sqrt{ }$ & 0.29 & 0.14 & 0.16 & 0.11 \\
\hline & $\sqrt{ }$ & $1000-1300 \mathrm{~cm}^{-1}$ & & 0.22 & 0.19 & 0.19 & 0.10 \\
\hline
\end{tabular}

\footnotetext{
$1 \sqrt{ }$ indicates that the corresponding interval is included in the model. The lowest prediction error is
} indicated in bold.

\section{CONCLUSIONS}

The results presented in this work show the potential usefulness of MIR FTIR/ATR spectroscopy for determining raw milk protein content. The water subtraction procedure presented allowed for a significant reduction in the interference due to water, which is the primary obstacle to the determination of protein concentration in an aqueous medium. However, whereas accurate water subtraction sufficed for the determination of protein concentration in aqueous solution, raw milk spectra were also influenced by other constituents, such as fat and lactose, which affect protein-water interactions, and can potentially form a "buffer layer" between the ATR crystal and the protein cells (Chittur, 1998; Farhat et al., 1998). These interactions were most probably responsible for the relatively high prediction errors obtained with PLS, namely no less than $0.20 \%$ protein, which corresponds to roughly $10 \%$ of the normal range. The lowest prediction errors were obtained when the spectral region associated with amide II and the spectral region associated with phospho-seryl, which is characteristic to casein, were included in the model. The prediction errors were greatly reduced (less than $0.10 \%$ protein) by taking into account the fat and lactose concentrations. Whereas in the present study these concentrations were added as external (nonspectral) inputs, this information could be obtained from the spectrum itself. For instance, fat expression can be determined from the 2800 to $3000 \mathrm{~cm}^{-1}$ range (Lefèvre and Subirade, 2000). In view of the current results, the next challenge is to combine information from several MIR ranges, not necessarily related directly to protein but to other milk constituents that interact with protein, to obtain a model based on the MIR spectrum alone.

\section{ACKNOWLEDGMENTS}

The authors wish to thank M. Gibbs, head of The Central Laboratory for Milk Analysis, Caesarea Industrial Park, for her help in preparing the standards. R. Linker acknowledges the financial support of the Lady Davis Foundation.

Table 5. Validation of the best model obtained using milk standards on fresh raw milk from 10 cows.

\begin{tabular}{|c|c|c|c|c|c|}
\hline \multirow[b]{2}{*}{ Cow number } & \multicolumn{3}{|c|}{ Reference analysis } & \multirow{2}{*}{$\begin{array}{l}\text { Prediction } \\
\% \text { protein }\end{array}$} & \multirow{2}{*}{$\begin{array}{l}\text { Prediction error } \\
\% \text { protein }\end{array}$} \\
\hline & $\%$ protein & $\%$ fat & $\%$ lactose & & \\
\hline 1 & 3.05 & 5.09 & 4.68 & 3.46 & 0.41 \\
\hline 2 & 3.26 & 1.25 & 4.97 & 3.06 & -0.20 \\
\hline 3 & 3.18 & 5.61 & 4.68 & 3.33 & 0.15 \\
\hline 4 & 2.84 & 2.27 & 4.59 & 3.01 & 0.17 \\
\hline 5 & 2.89 & 4.25 & 4.64 & 3.38 & 0.49 \\
\hline 6 & 2.15 & 11.27 & 4.50 & 3.10 & 0.95 \\
\hline 7 & 3.95 & 4.14 & 4.54 & 3.49 & -0.46 \\
\hline 8 & 2.96 & 4.64 & 3.71 & 3.02 & 0.08 \\
\hline 9 & 3.16 & 3.18 & 5.06 & 3.11 & -0.05 \\
\hline 10 & 2.95 & 2.34 & 4.9 & 3.07 & 0.12 \\
\hline
\end{tabular}




\section{REFERENCES}

Andersen, S. K., P. W. Hansen, and H. V. Andersen. 2002. Vibrational spectroscopy in the analysis of dairy products and wine. In Handbook of Vibrational Spectroscopy. J. M. Chalmer and P. R. Griffiths ed. John Wiley \& Sons, Chichester, UK. Available at http:// www.kursus.kvl.dk/shares/milk/300_pensum/vibrational spectroscopy.pdf. Accessed Aug. 1, 2003.

Chittur, K. K. 1998. FTIR and protein structure at interfaces. Biomaterials 19:357-369.

Coates J. 2000. Interpretation of infrared spectra, a practical Approach. In Encyclopedia of Analytical Chemistry, R. A. Meyers ed. John Wiley \& Sons, Chichester, UK. Available at http://ww w.spectroscopynow.com/Spy/basehtml/SpyH/1,,3-1-4-2-0-news archive list-0-0,00.html. Accessed July 15, 2004.

Curley, D. M., T. F. Kumosinski, J. J. Unruh, and H. M. Farrell, Jr. 1998. Effect of calcium and temperature on casein. J. Dairy Sci. 81:3154-3162.

DePeters, E. J., and J. D. Ferguson. 1992. Nonprotein nitrogen and protein distribution in milk of cows. J. Dairy Sci. 75:3192-3209.

Dousseau, F., and M. Pézolet. 1990. Determination of the secondary structure content of proteins in aqueous solutions from their amide I and amide II Infrared bands. Comparison between classical and partial least squares methods. Biochemistry 29:8771-8779.

Dousseau, F., M. Therien, and M. Pézolet. 1989. On the spectral subtraction of water from the FT-IR spectra of aqueous solutions of proteins. Appl. Spectrosc. 43:538-542.

Farhat, I. A., S. Orset, P. Moreau, and J. M. V. Blanshard. 1998. FTIR study of hydration phenomena in protein-sugar systems. J. Colloid Interface Sci. 207:200-208.

Fidencio, P. H., R. J. Poppi, and J. C. de Andrade. 2002. Determination of organic matter in soils using radial basis function networks and near infrared spectroscopy. Anal. Chem. Acta 4583:125-134.

Grdadolnik, J., and Y. Maréchal. 2001. Bovine serum albumin observed by infrared spectrometry. II. Hydration mechanisms and interaction configurations of embedded $\mathrm{H}_{2} \mathrm{O}$ molecules. Biopolymers 62:54-67.

Griffiths, P. R. and J. A. deHaseth. 1986. Fourier transform infrared spectroscopy. Chemical Analysis. Vol. 83. John Wiley InterScience, New York, NY.

Haaland, D. M., and E. V. Thomas. 1988. Partial least-squares methods for spectral analysis. 1. Relation to other quantitative calibration methods and the extraction of qualitative information. Anal. Chem. 60:1193-1202.

Haykin, S. 1999. Neural Networks. A Comprehensive Foundation. Prentice Hall, Upper Saddle River, NJ.

Hewavitharana, A. K., and B. V. Brakel. 1997. Fourier transform infrared spectrometric method for rapid determination of casein in raw milk. Analyst 122:701-704.

Jolliffe, I. T. 1986. Principal Component Analysis. Springer-Verlag, New York, NY.
Jung, C. 2000. Insight into protein structure and protein-ligand recognition by Fourier transform infrared spectroscopy. J. Mol. Recognit. 13:325-351.

Kemsley, E. K., G. P. Eppleton, and R. H. Wilson. 1994. Quantitative analysis of emulsion using attenuated total reflectance (ATR). Spectrochem. Acta 50A:1235-1242.

Lefèvre, T., and M. Subirade. 2000. Interaction of $\beta$-lactoglobulin with phospholipids bilayers: A molecular level elucidation as revealed by infrared spectroscopy. Int. J. Biol. Macromol. 28:59-67.

Libnau, F. O., O. M. Kvalheim, A. A. Christy, and J. Toft. 1994. Spectra of water in the near- and mid-infrared region. Vib. Spectrosc. 7:243-254.

Mariey, L., J. P. Signolle, C. Amiel, and J. Travert. 2001. Discrimination, classification, identification of microorganisms using FTIR spectroscopy and chemometrics. Vib. Spectrosc. 26:151-159.

Melling, J. M., and M. Thompson. 2002. Fiber-optic probes for midinfrared spectrometry. In Handbook of Vibrational Spectroscopy. J. M. Chalmer and P. R. Griffiths, ed. John Wiley \& Sons, Chichester, UK. Available at http://www.remspec.com/pdfs/2703_o.pdf. Accessed July 15, 2004.

Messica, A., A. Greenstein, and A. Katzir. 1996. Theory of fiberoptic, evanescent-wave spectroscopy and sensors. Appl. Optics 35:2274-2284.

Powell, J. R., F. F. Wasacz, and R. J. Jakobsen. 1986. An algorithm for the reproducible spectral subtraction of water from the FTIR spectra of proteins in dilute solutions and absorbed monolayers. Appl. Spectrosc. 40:339-344.

Rahmelow, K., and W. Hübner. 1997. Infrared spectroscopy in aqueous solution: Difficulties and accuracy of water subtraction. Appl. Optics 51:160-170.

Ramon, O., E. Kesselman, R. Berkovich, Y. Cohen, and Y. Paz. 2001. Attenuated total reflectance/Fourier transform infrared studies on the phase-separation process of aqueous solutions of $\operatorname{poly}(N$ isopropylacrylamide). J. Polymer Sci.: Part B: Polym. Phys. 39:1665-1677.

Ruckebusch, C., B. Sombret, R. Froidevaux, and J.-P. Huvenne. 2001. On-line mid-infrared spectroscopy data and chemometrics for the monitoring of an enzymatic hydrolysis. Appl. Spectrosc. $55: 1610-1617$.

Schmilovich, Z., I. Shmulevich, A. Notea, and E. Maltz. 2000. Near infrared spectroscopy of milk in its heterogeneous state. Comp. Elec. Agric. 29:195-207.

Susi, H. 1969. Infrared spectra of biological macromolecules and related systems. Pages 575-663 in Structure and Stability of Biological Macromolecules. S. N. Timasheff and G. D. Fasman, ed. Marcel Dekker, New York, NY.

Swaisgood, H. E. 1996. Characteristics of milk. Pages 841-878 in Food Chemistry. 3rd ed. O. R. Fennema, ed. Marcel Dekker, New York, NY.

Timasheff, S. N., and G. D. Fasman. 1969. Structure and Stability of Biological Macromolecules. Marcel Dekker, New York, NY.

Wold, S. 1995. Chemometrics: What do we mean with it, and what do we want from it? Chemom. Intell. Lab. Sys. 30:109-115. 